\title{
Prevalence and predictors of late presentation for HIV care in South Africa
}

\author{
H N Fomundam, ${ }^{1}$ PharmD; A R Tesfay, ${ }^{1}$ MSc (Med); S A Mushipe,,${ }^{1}$ MPH; M B Mosina, ${ }^{1}$ BSc; C T Boshielo, ${ }^{1}$ MPH; $\mathbf{H}$ T Nyambi, ${ }^{1}$ BA; \\ A Larsen, ${ }^{2} \mathrm{MPH} ;$ M Cheyip, ${ }^{2} \mathrm{MSc}$ (Med); A Getahun, ${ }^{2} \mathrm{MD}, \mathrm{MPH} ; \mathrm{Y}$ Pillay, ${ }^{3} \mathrm{PhD}$ \\ ${ }^{1}$ Howard University Global Initiative South Africa, Howard University, Pretoria, South Africa \\ ${ }^{2}$ Division of Global HIV/AIDS and Tuberculosis, Centers for Disease Control and Prevention, Pretoria, South Africa \\ ${ }^{3}$ Strategic Health Programmes, National Department of Health, Pretoria, South Africa
}

Corresponding author: A R Tesfay (abrahamrezene@yahoo.com)

\begin{abstract}
Background. Many people living with HIV in South Africa (SA) are not aware of their seropositive status and are diagnosed late during the course of HIV infection. These individuals do not obtain the full benefit from available HIV care and treatment services.

Objectives. To describe the prevalence of late presentation for HIV care among newly diagnosed HIV-positive individuals and evaluate sociodemographic variables associated with late presentation for HIV care in three high-burden districts of SA.

Methods. We used data abstracted from records of 8138 newly diagnosed HIV-positive individuals in 35 clinics between 1 June 2014 and 31 March 2015 to determine the prevalence of late presentation among newly diagnosed HIV-positive individuals in selected highprevalence health districts. Individuals were categorised as 'moderately late', 'very late' or 'extremely late' presenters based on specified criteria. Descriptive analysis was performed to measure the prevalence of late presentation, and multivariate regression analysis was conducted to identify variables independently associated with extremely late presentation.

Results. Overall, $79 \%$ of the newly diagnosed cases presented for HIV care late in the course of HIV infection (CD4+ count $\leq 500$ cells/ $\mu \mathrm{L}$ and/or AIDS-defining illness in World Health Organization (WHO) stage III/IV), 19\% presented moderately late (CD4+ count 351 500 cells $/ \mu \mathrm{L}$ and WHO clinical stage I or II), 27\% presented very late (CD4+ count $201-350$ cells $/ \mu \mathrm{L}$ or WHO clinical stage III), and 33\% presented extremely late (CD4+ count $\leq 200$ cells $/ \mu \mathrm{L}$ and/or WHO clinical stage IV) for HIV care. Multivariate regression analysis indicated that males, non-pregnant women, individuals aged $>30$ years, and those accessing care in facilities located in townships and inner cities were more likely to present late for HIV care.

Conclusions. The majority of newly diagnosed HIV-positive individuals in the three high-burden districts (Gert Sibande, uThukela and City of Johannesburg) presented for HIV care late in the course of HIV infection. Interventions that encourage early presentation for HIV care should be prioritised in SA and should target males, non-pregnant women, individuals aged $>30$ years and those accessing care in facilities located in inner cities and urban townships.
\end{abstract}

S Afr Med J 2017;107(12):1058-1064. DOI:10.7196/SAMJ.2017.v107i12.12358

More than 6.4 million people are currently living with HIV infection in South Africa (SA), and 400000 new HIV infections occur each year. ${ }^{[1]}$ With the adoption of policies such as nurse-initiated management of antiretroviral therapy (ART) services and the re-engineering of primary healthcare, SA has managed to rapidly expand ART services to people living with HIV. ${ }^{[1]}$ Massive HIV counselling and testing (HCT) campaigns have been conducted since 2010 to hasten diagnosis and facilitate early presentation to care, but a significant number of people living with HIV are still diagnosed late during the course of HIV infection. ${ }^{[2]}$

Universal HIV therapy leading to viral suppression is critical to ending the HIV epidemic in SA and other parts of the world. ${ }^{[3]}$ People living with HIV can derive maximum benefit from ART if they are diagnosed and receive treatment early in the course of HIV infection ${ }^{[4]}$ The SA government has adopted the Joint United Nations Programme on HIV/AIDS (UNAIDS) 90-90-90 strategy: diagnosing $90 \%$ of people living with HIV, putting $90 \%$ of people with diagnosed HIV on treatment, and achieving viral suppression in $90 \%$ of people receiving ART services by $2020 .{ }^{[3]}$

Despite effective treatment services, data from the 2014 national population-based HIV survey in SA indicated that $62 \%$ of men and $45 \%$ of women living with HIV infection had yet to be diagnosed and were not aware of their seropositive status. ${ }^{[1]}$ The prevalence of late presentation for HIV care ranges from $30 \%$ in developed countries to $>70 \%$ in African countries. ${ }^{[-7]}$ A study conducted in Brazil showed that $\sim 40 \%$ of HIV-infected individuals presented late for HIV care, $70 \%$ of the late presenters had severe clinical and immunological impairment, and $\sim 30 \%$ were diagnosed only at death. ${ }^{[8]}$

People living with HIV infection can achieve viral suppression if they receive sustained combination ART. ${ }^{[9,10]} \mathrm{HIV}$-infected individuals on ART are less likely to transmit HIV infection to their sexual partners than those who are not on ART, as ART can lead to viral suppression and significantly reduce the risk of sexual transmission of HIV infection. ${ }^{[11,12]}$

Early initiation of ART during the asymptomatic phase of the HIV infection can also greatly reduce the risk of progression to symptomatic HIV disease and death. ${ }^{[13]}$ Late presentation for HIV care is associated with an increased likelihood of progression to AIDS. HIV-positive individuals who present late for HIV care also experience an increased risk of mortality. ${ }^{[14-18]}$ It has been reported that premature death due to late presentation for HIV care accounts for $\sim 40 \%$ of all AIDS-related deaths. ${ }^{[19]}$ Management of individuals living with HIV who present late for care with advanced clinical manifestations of AIDS and severely compromised immune systems 
is extremely expensive, as they suffer more morbidity and utilise more medical care resources than similar patients who present early. ${ }^{[20]}$ Epidemiological data indicate that ART significantly reduces the risk of HIV transmission in heterosexual serodiscordant couples. ${ }^{[11,21]}$ The incidence of HIV infection decreased over time in locations where a high level of ART coverage was achieved through successful scale-up of HIV treatment services. ${ }^{[10,22,23]}$

\section{Objectives}

To describe late presentation for HIV care among newly diagnosed HIV-positive individuals based on disease progression and to identify potential predictors of late presentation for HIV care.

\section{Methods}

This study was conducted in 35 purposefully selected primary healthcare (PHC) clinics. The clinics were selected from three high HIV burden districts of SA (Gert Sibande, uThukela and City of Johannesburg). PHCs that could generate quality clinical data (phase 6) for newly diagnosed HIV-positive individuals were identified in each district. PHC clinics were selected based on the prevalence of HIV, the HIV positivity rate and the quality of clinical data available in the clinics. All newly diagnosed HIV-positive individuals aged $\geq 12$ years who received their first positive test result for HIV between 1 June 2014 and 31 March 2015 were included in this study, in line with the HCT guideline of SA. ${ }^{[2]}$ Newly diagnosed HIV-positive individuals with missing CD4+ measurements in their clinical records were excluded from the analysis. Data on sociodemographic and clinical variables of newly diagnosed HIV cases were collected. Facilities were classified into rural, urban township, urban suburb or urban inner city, based on the location of the facility. Facilities in rural settlements away from cities and towns where agriculture is the mainstay of the economic activities were classified as 'rural'. Facilities located in a central business district of an urban setting were classified as 'urban inner city'. Statistics South Africa classification of household income was used to classify urban facilities further into 'urban township' and 'urban suburb'. ${ }^{[25]}$ Facilities located in a formal settlement of middle-income communities were classified as 'urban township'. Facilities located in a suburb of upper-income communities were classified as 'urban suburb'. Other sociodemographic data such as education, employment and income are not routinely documented in clinical records, so were not included in this study. Clinical data related to HCT and clinical screening and laboratory monitoring services provided to newly diagnosed HIV-positive individuals were collected from various clinical registers and records through clinical record review using a standardised case record form. Computerised data quality verification was performed using STATA version 14.1 software (StataCorp, USA) to detect and correct data entry errors. The dataset was analysed to determine the prevalence and predictors of late presentation for HIV care.

Late presentation for HIV care was largely defined based on the 2014 HIV treatment guideline of SA. ${ }^{[2]}$ Cues were also taken from historical SA ART guidelines to determine the cut-off point when classifying late presenters into three subcategories based on CD4+ measurement and World Health Organization (WHO) clinical staging. The 2014 ART guideline suggests that people living with $\mathrm{HIV}$ who enter care with a CD4+ count of $\leq 500$ cells $/ \mu \mathrm{L}$ are unable to benefit fully from ART, so are considered late presenters. WHO clinical staging and CD4+ measurement are both independent parameters that assist clinicians to determine ART eligibility of newly diagnosed HIV cases. ${ }^{[26]}$

For the purpose of this analysis, late presentation for HIV care refers to an HIV-positive individual whose HIV diagnosis was done when the CD4+ cell count had dropped to $\leq 500$ cells/ $\mu \mathrm{L}$ and/or who had clinical manifestations of AIDS at the time of diagnosis. ${ }^{[24,26]}$ Fig. 1 shows the matrix used to classify late presenters further into 'moderately late presentation', 'very late presentation' and 'extremely late presentation', based on level of disease progression measured by CD4+ count and WHO clinical staging. Newly diagnosed HIVpositive individuals with a baseline CD4+ count of 351 - 500 cells/ $\mu \mathrm{L}$, excluding those presenting with clinical manifestations of AIDS in WHO stage III or IV, were classified as having moderately late presentation for HIV care. Newly diagnosed HIV-positive individuals with clinical manifestations of AIDS in WHO clinical stage III irrespective of CD4+ count, and/or with a CD4+ count

\begin{tabular}{|c|c|c|c|c|c|c|}
\hline \multirow{2}{*}{\multicolumn{2}{|c|}{ WHO clinical stage }} & \multicolumn{5}{|c|}{ 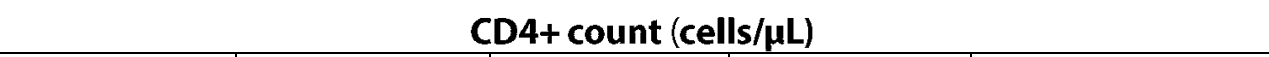 } \\
\hline & & $\leq 200$ & $201-350$ & $351-500$ & $>500$ & Count unknown \\
\hline \multicolumn{2}{|l|}{ Stage IV } & & & & & \multirow{5}{*}{$\begin{array}{c}\text { Excluded from the } \\
\text { analysis }\end{array}$} \\
\hline \multicolumn{2}{|l|}{ Stage III } & & & & & \\
\hline \multicolumn{2}{|l|}{ Stage II } & & & & & \\
\hline \multicolumn{2}{|l|}{ Stage I } & & & & & \\
\hline \multicolumn{2}{|c|}{ Stage unknown } & & & & & \\
\hline \multicolumn{7}{|l|}{ Key } \\
\hline & \multicolumn{6}{|c|}{$\begin{array}{l}\text { Extremely late presentation. Newly diagnosed cases presenting with clinical manifestation of AIDS in WHO clinical stage IV } \\
\text { irrespective of CD4+ count, and/or with a CD4+ count of } \leq 200 \text { cells/ } \mu \text { L irrespective of WHO staging }\end{array}$} \\
\hline & \multicolumn{6}{|c|}{$\begin{array}{l}\text { Very late presentation. Newly diagnosed cases presenting with clinical manifestation of AIDS in WHO clinical stage III } \\
\text { irrespective of CD4+ count and/or with a CD4+ count of } 201-350 \text { cells/ } \mu \mathrm{L} \text {, excluding those presenting in WHO stage IV }\end{array}$} \\
\hline & \multicolumn{6}{|c|}{$\begin{array}{l}\text { Moderately late presentation. Newly diagnosed cases presenting with a baseline CD4+ count of } 351-500 \text { cells/ } \mu \mathrm{L} \text {, excluding } \\
\text { those presenting with clinical manifestations of AIDS in WHO stage III or IV }\end{array}$} \\
\hline & \multicolumn{6}{|c|}{$\begin{array}{l}\text { Early presentation. Newly diagnosed cases presenting with a baseline CD4+ count of }>500 \text { cells/ } \mu \mathrm{L} \text {, excluding those } \\
\text { presenting with clinical manifestation of AIDS in WHO stage III or IV }\end{array}$} \\
\hline
\end{tabular}

Fig. 1. Classification matrix for late presenters. (WHO = World Health Organization.) 
of $201-350$ cells $/ \mu \mathrm{L}$, excluding those presenting in WHO stage IV, were classified as having very late presentation for HIV care. Newly diagnosed HIV-positive individuals presenting with clinical manifestations of AIDS in WHO clinical stage IV irrespective of CD4+ count, and/or with a CD4+ count $\leq 200$ cells/ $\mu \mathrm{L}$ irrespective of WHO staging, were classified as having extremely late presentation for HIV care. Individuals whose CD4+ count was missing were excluded from the analysis. Those who were not clinically staged according to WHO staging were classified based on CD4+ count criteria alone.

A cross-sectional analysis to determine the proportion of newly diagnosed HIV-positive individuals presenting late for HIV care was computed using the definitions outlined above. The distribution of late presentation was examined by sex, age group, pregnancy status, health facility, district and facility location using $x^{2}$ tests. Special emphasis was given to the 'extremely late presentation' outcome, and further analysis was carried out to identify variables associated with this outcome. Univariate regression analysis was performed to examine associations between extremely late presentation for HIV care and sociodemographic variables. Multivariate logistic regression analysis was conducted to identify variables independently associated with extremely late presentation for HIV care. Variables were included in the regression model using a backward elimination approach. A $p$-value of $>0.05$ was used to eliminate variables that did not show significant effect from the model. Individuals with missing CD4+ counts were excluded from the analysis.

The protocol for the pre-ART surveillance project was approved by the Associate Director of Science at the US Centers for Disease Control and Prevention, Division of Global HIV/AIDS and Tuberculosis (ref. no. 00000891) and by the Research Ethics Committee at the School of Health Sciences and Public Health at the University of Pretoria (ref. no. 169/2013). Howard University also obtained relevant permissions from the national and the respective provincial departments of health of SA.

\section{Results}

We identified 12413 newly diagnosed HIV-positive individuals in 35 PHC facilities who were eligible for inclusion in the analysis based on the criteria outlined under 'Methods'. About $34 \%$ of these individuals were excluded from the analysis owing to missing CD4+ counts in their clinical records. Generally, the sex distribution of individuals who were excluded from the study was similar to that of those who were included, with the majority of newly diagnosed HIV-positive individuals being women (69\%). There was also no major difference between individuals included in the study and individuals excluded in terms of age distribution, pregnancy status and district. Most (73\%) of the newly diagnosed individuals were between the ages of 21 and 40 years (Table 1 ).

WHO clinical staging information was available for $47 \%$ of the study subjects, of whom $<1 \%$ were classified as stage IV and $6 \%$ as stage III. About $32 \%$ of study subjects had a recorded baseline CD $4+$ count $\leq 200$ cells $/ \mu \mathrm{L}$ and $22 \%$ a CD $4+$ count $>500$ cells $/ \mu \mathrm{L}$. About three-quarters of newly diagnosed individuals were known to be eligible for ART initiation at the date of diagnosis based on the national ART eligibility guideline. ${ }^{[24]}$ Overall, more than three-

Table 1. Characteristics of newly diagnosed HIV-positive cases presenting late for HIV care in three high-burden districts of South Africa, June 2014 - March 2015

\begin{tabular}{|c|c|c|c|c|c|}
\hline \multirow[b]{2}{*}{ Sociodemographic variables } & \multicolumn{5}{|c|}{ Presentation categories } \\
\hline & $\begin{array}{l}\text { Total HIV } \\
\text { cases, } N\end{array}$ & $\begin{array}{l}\text { Early presentation, } \\
n(\%)\end{array}$ & $\begin{array}{l}\text { Moderately late } \\
\text { presentation, } n(\%)\end{array}$ & $\begin{array}{l}\text { Very late } \\
\text { presentation, } n(\%)\end{array}$ & $\begin{array}{l}\text { Extremely late } \\
\text { presentation, } n(\%)\end{array}$ \\
\hline \multicolumn{6}{|l|}{ Sex } \\
\hline Female & 5601 & $1411(25.2)$ & $1189(21.2)$ & $1506(26.9)$ & 1495 (26.7) \\
\hline Male & 2533 & $350(13.8)$ & $367(14.5)$ & $663(26.2)$ & $1153(45.5)$ \\
\hline \multicolumn{6}{|l|}{ Age category (yr) } \\
\hline $12-20$ & 665 & $193(29.0)$ & $159(23.9)$ & $192(28.9)$ & $121(18.2)$ \\
\hline $21-30$ & 3421 & $890(26.0)$ & $730(21.3)$ & $937(27.4)$ & $864(25.3)$ \\
\hline $31-40$ & 2484 & $422(17.0)$ & 432 (17.4) & $675(27.2)$ & $955(38.4)$ \\
\hline $41-50$ & 1073 & $184(17.1)$ & $169(15.8)$ & $236(22.0)$ & $484(45.1)$ \\
\hline$>50$ & 467 & $67(14.3)$ & $61(13.1)$ & $116(24.8)$ & $223(47.8)$ \\
\hline \multicolumn{6}{|l|}{ Pregnancy } \\
\hline Yes & 1640 & $446(27.2)$ & $448(27.3)$ & $472(28.8)$ & $274(16.7)$ \\
\hline No & 3374 & $789(23.4)$ & $611(18.1)$ & $914(27.1)$ & $1060(31.4)$ \\
\hline \multicolumn{6}{|l|}{ District } \\
\hline Gert Sibande & 3145 & $635(20.2)$ & $595(18.9)$ & $924(29.4)$ & $991(31.5)$ \\
\hline Johannesburg & 2306 & $401(17.4)$ & $455(19.7)$ & $584(25.3)$ & $866(37.6)$ \\
\hline uThukela & 2687 & $726(27.0)$ & $507(18.9)$ & $664(24.7)$ & $790(29.4)$ \\
\hline \multicolumn{6}{|l|}{ Location of facilities } \\
\hline Rural & 1388 & $380(27.4)$ & $266(19.2)$ & $334(24.1)$ & $408(29.4)$ \\
\hline Urban suburb & 1478 & $364(24.6)$ & $251(17.0)$ & $387(26.2)$ & $476(32.2)$ \\
\hline Urban township & 4983 & $959(19.2)$ & $987(19.8)$ & $1393(28.0)$ & $1644(33.0)$ \\
\hline Urban inner city & 289 & $59(20.4)$ & $53(18.3)$ & $58(20.1)$ & $119(41.2)$ \\
\hline Total HIV cases & 8138 & $1762(21.7)$ & 1557 (19.1) & 2172 (26.7) & $2648(32.5)$ \\
\hline
\end{tabular}


Table 2. Proportions of newly diagnosed HIV-positive individuals presenting extremely late HIV care in three high-burden districts in South Africa, disaggregated by age and sex, June 2014 - March 2015

\begin{tabular}{|c|c|c|c|c|}
\hline \multirow[b]{2}{*}{ Age category (yr) } & \multicolumn{2}{|c|}{ Total newly diagnosed HIV cases, $N$} & \multicolumn{2}{|c|}{ Extremely late presenters, $n(\%)$} \\
\hline & Female & Male & Female & Male \\
\hline $12-20$ & 586 & 79 & $90(15.4)$ & $31(39.2)$ \\
\hline $21-30$ & 2663 & 750 & $587(22.0)$ & $272(36.3)$ \\
\hline $31-40$ & 1465 & 1012 & $483(33.0)$ & $466(46.0)$ \\
\hline $41-50$ & 613 & 460 & $228(37.2)$ & $256(55.7)$ \\
\hline$>50$ & 245 & 221 & $100(40.8)$ & $123(55.7)$ \\
\hline Total & 5572 & 2522 & $1488(26.7)$ & $1148(45.5)$ \\
\hline
\end{tabular}

quarters of the study cases presented late for HIV care, with $19 \%$ presenting moderately late (CD4+ count $351-500$ cells/ $\mu \mathrm{L}$ and/ or WHO clinical stage I or II), $27 \%$ presenting very late (CD4+ count 201 - 350 cells/ $\mu \mathrm{L}$ and/or WHO clinical stage III), and 33\% presenting extremely late (CD4+ count $\leq 200$ cells/ $\mu \mathrm{L}$ and/or WHO clinical stage IV).

A subanalysis was conducted to describe extremely late presentation among newly diagnosed HIV-positive individuals by gender and age. Generally, the proportion of males presenting extremely late for HIV care was much higher than that of females across all age categories. More than half of males aged $\geq 40$ years presented for HIV care extremely late with a CD4+ count $\leq 200$ cells/ $\mu \mathrm{L}$ and/or WHO clinical stage IV. The widest gap between the proportion of males and females presenting extremely late for HIV care was observed in the age category 12 - 20 years, in which the proportion of males exceeded the proportion of females by $24 \%$ (Table 2 ).

Multivariate logistic regression analysis was conducted to determine the likelihood of extremely late presentation for HIV care at each level v. the likelihood of early presentation. Males were far more likely than their female counterparts to present extremely late (adjusted odds ratio (AOR) 2.7, 95\% confidence interval (CI) 1.5 - 4.9) v. early. The analysis showed a strong association between age at diagnosis and extremely late presentation. Newly diagnosed HIV-positive individuals aged $\geq 51$ years were more likely to present extremely late for HIV care compared with individuals in the age group 12 - 20 years (AOR 3.4, 95\% CI $2.4-4.9$ ). Similarly, individuals aged $30-50$ years were at least 2.6 times more likely to present extremely late for HIV care compared with individuals in the age group 12 - 20 years. Pregnant women were less likely to present extremely late for HIV care compared with women who were not pregnant (AOR 0.53, 95\% CI 0.44 - 0.64). Newly diagnosed HIV-positive individuals accessing care in facilities located in urban townships (AOR 1.6, 95\% CI 1.4 - 1.5) and inner cities (AOR 1.5, 95\% CI 1.1 - 2.2) were more likely to present extremely late for HIV care compared with HIV-positive individuals accessing care in rural facilities (Table 3).

\section{Discussion}

The current analysis shows that a third of newly diagnosed HIV-positive individuals were not effectively linked to HIV care and/or did not have a documented CD4+ result. There are two possible explanations for the observed gap in the clinical data. Most newly diagnosed HIVpositive individuals with missing or incomplete clinical records may be considered early losses to follow-up. This may represent a real gap in clinical service delivery. The current data show that a third of newly diagnosed HIV-positive individuals did not gain immediate benefit from available healthcare services. Similar rates of loss to follow-up have been reported among newly diagnosed HIV-positive individuals
Table 3. Sociodemographic variables and the likelihood of extremely late presentation for HIV care among newly diagnosed HIV-positive individuals in three high-burden districts of South Africa, June 2014 - March 2015

\begin{tabular}{|c|c|c|c|}
\hline \multirow{2}{*}{$\begin{array}{l}\text { Sociodemographic } \\
\text { variables }\end{array}$} & \multirow{2}{*}{$\begin{array}{l}\text { Early } \\
\text { presenters, } n\end{array}$} & \multicolumn{2}{|c|}{ Extremely late presenters } \\
\hline & & $n$ & AOR (95\% CI) \\
\hline \multicolumn{4}{|l|}{ Sex } \\
\hline Female & 1411 & 1503 & 1 \\
\hline Male & 350 & 1153 & $2.73(1.50-4.94)$ \\
\hline \multicolumn{4}{|l|}{ Age (yr) } \\
\hline $12-20$ & 193 & 121 & 1 \\
\hline $21-30$ & 890 & 864 & $1.34(1.04-1.73)$ \\
\hline $31-40$ & 422 & 955 & $2.6(1.99-3.39)$ \\
\hline $41-50$ & 184 & 486 & $2.72(2.02-3.66)$ \\
\hline$>50$ & 67 & 223 & $3.4(2.35-4.92)$ \\
\hline \multicolumn{4}{|l|}{ Pregnancy } \\
\hline No & 446 & 274 & 1 \\
\hline Yes & 789 & 1060 & $0.53(0.44-0.64)$ \\
\hline \multicolumn{4}{|l|}{ Location of facilities } \\
\hline Rural & 380 & 408 & 1 \\
\hline Urban inner city & 364 & 476 & $1.52(1.06-2.20)$ \\
\hline Urban suburb & 959 & 1644 & $1.16(0.94-1.43)$ \\
\hline Urban township & 59 & 119 & $1.59(1.34-1.90)$ \\
\hline
\end{tabular}

in other studies. ${ }^{[27,28]}$ Recording and transcription errors may also result in crucial clinical data being missed. Substandard clinical data can compromise the ability to research and understand the provision of quality healthcare. ${ }^{[29]}$ Clinical record systems need continuous improvement to reflect the state of the healthcare system accurately and assist in rational decision-making.

More than three-quarters of the 8138 newly diagnosed HIVpositive individuals in this study presented late for HIV care with a CD $4+$ count $\leq 500$ cells $/ \mu \mathrm{L}$ and/or WHO clinical stage III/IV disease, and one-third presented extremely late for HIV care with a CD4+ count of $\leq 200 \mathrm{cells} / \mu \mathrm{L}$ and/or WHO clinical stage IV disease. Sex, age and pregnancy status were independently associated with the likelihood of late presentation for HIV care. Late presentation for HIV care tended to be more prevalent among males, older people, non-pregnant women and individuals accessing care in facilities located in inner cities and urban townships compared with females, younger people, pregnant women and individuals accessing care 
in rural facilities. These findings are consistent with what has been observed in other studies, taking into account differences in the definition of the term 'late presentation. ${ }^{[5-7,30]}$ An attempt was made to provide a more detailed description of presentation to care by looking into the full spectrum spanning from early presentation to extremely late presentation and analysing the subcategories across sociodemographic groups.

The present study found that the prevalence of late presentation for HIV care was exceptionally high among males in general, and older males in particular, compared with their female or younger counterparts. This finding is consistent with similar studies from $\mathrm{SA}^{[28]}$ and elsewhere in the sub-Saharan African region. ${ }^{[30-33]}$ While the national scale-up of ART in SA has resulted in gains in life expectancy for both men and women, the gains have disproportionately benefited women, further confirming that men are failing to interact with the health system early enough to improve their health outcomes. ${ }^{[34,35]}$ These studies collectively highlight an urgent need to target men, and in particular older men, to encourage uptake of HIV testing with the ultimate goal of reducing late presentation for HIV care.

The differential in late presentation by sex and age has been explained in prior studies as the combined effects of social norms, ${ }^{[31-37]}$ health knowledge ${ }^{[32,38]}$ age-specific progression of disease ${ }^{[34-38]}$ and the policy environment. ${ }^{[39]}$ Social constructs of masculinity were cited as a barrier to health-seeking in Zimbabwe ${ }^{[36]}$ while a study conducted across sub-Saharan Africa found that men aged $>50$ years exhibited a disproportionately low level of knowledge of $\mathrm{HIV} \cdot{ }^{[38]}$ Previous studies note evidence that seroconversion at older ages is associated with more aggressive disease progression, so that individuals infected later in life are more likely than those infected at a younger age to present for HIV care with lower CD4+ counts. Other factors that may also play a role in delaying HIV testing among older males include fear and stigma associated with HIV infection, alcohol and drug abuse, traditional beliefs associated with HIV, language and cultural obstacles. $^{[40]}$ Some barriers are modifiable, and a combination of strategies directed at both individual and social levels can ameliorate the observed late presentation of older men to HIV care.

It is important to note that younger males in the age group 12 20 years experienced a disproportionately higher prevalence of extremely late presentation for HIV care compared with their female counterparts in the same age group. Women in their teens are more likely than males to interact with the healthcare system as they seek reproductive healthcare. Survey data indicate that $\sim 30 \%$ of teenage women in SA reported ever having been pregnant. ${ }^{[41]}$ Pregnancy can facilitate early diagnosis of HIV, as HCT services are routinely offered to all pregnant women during antenatal care. ${ }^{[42]}$ Teenage males do not benefit from similar interventions that can hasten HIV diagnosis. An innovative strategy is therefore needed to facilitate access to healthcare services for young males.

The current analysis also shows that the rate of late presentation for HIV care is higher in facilities located in inner cities and urban townships than in facilities in rural areas. Migration patterns and several barriers to care may explain the observed findings. Workrelated internal migration is common in SA, especially among older males. People migrate from their rural homes to urban centres in search of work and better living conditions. ${ }^{[33]}$ This phenomenon has increased the burden of care in urban health facilities, resulting in congestion and long waiting hours. ${ }^{[4]}$ Most health facilities do not cater for the specific needs of migrants, which include extending operational hours during weekdays and opening for service over the weekend. ${ }^{[45]}$ These factors may compromise access to care for people in inner cities and townships and discourage them from seeking HIV testing early, resulting in late presentation for HIV care.
Several other barriers have been reported to contribute to a high prevalence of late presentation for HIV care. Fear can be a significant barrier to early presentation, including fear of the disease itself, fear of disclosure and fear of subsequent social stigma, discrimination and criminalisation of risk behaviours. ${ }^{[46]}$ A study in Uganda suggested that close relatives of individuals who were assumed to be infected with HIV were less likely to seek HIV testing. ${ }^{[4]}$ Some beliefs and cultural norms associated with HIV, such as 'AIDS is caused by witchcraft', discourage people from seeking HIV testing and presenting to care early. ${ }^{[48]}$

It has been reported that premature death due to late presentation for HIV care accounts for $\sim 40 \%$ of all AIDS-related deaths. ${ }^{[49]}$ The results of this study highlight a profile of individuals that should be targeted by policies and programmes as a matter of urgency to encourage early presentation to HIV care and timely initiation of treatment, and ultimately to reduce viral load and prevent death from HIV/AIDS.

\section{Study limitations}

This study has some limitations that could have influenced the observed findings. The sample was not selected based on a probability sampling strategy. As such, the sample population may not be representative of the total population of newly diagnosed HIVpositive individuals in SA. Diverse facilities from urban, periurban and rural settings are represented in this analysis, which generated a large sample size. The results may be a reflection of presentation to care in SA. However, it may not be possible to extrapolate the findings to newly diagnosed individuals not included in the study. Presentation to care could not be determined for a third of newly diagnosed HIV-positive individuals owing to missing CD4+ counts. Exclusion of these individuals from the analysis could have influenced the observed outcome in either direction, depending on the distribution of missing data in the study population. This analysis was based on secondary data generated during routine clinical management of newly diagnosed HIV-positive individuals at participating facilities. The investigators could not independently ascertain the provision of services provided to HIV-positive individuals, or the lack thereof. An assumption was made that clinical records reflected service delivery. About half of the study participants did not have documented WHO staging and their presentation to HIV care was classified on the basis of CD4+ measurement alone, which may have resulted in misclassification of some cases. A study design that involved a statistically representative sample of newly diagnosed HIV-positive individuals and active collection of primary data instead of passively relying on clinical records could have improved the validity of this study and addressed the issue of missing data. We used CD4+ counts and WHO staging as markers to measure the time between HIV infection and HIV diagnosis, and a scale of presentation to care from early presentation to extremely late presentation was developed based on these markers. This could have introduced measuring bias, as the markers may not be accurate indicators of duration of HIV infection. Sociodemographic variables such as level of education, income and employment were not considered, as they are not generally reported in clinical records.

\section{Conclusions and recommendations}

Although this study used a purposeful sample, which is prone to selection bias, the researchers found no major differences in the independent variables between individuals included and those excluded from the study and decided to proceed with analysis. The findings of this study could be an indication of presentation to care in other high HIV-volume PHC facilities in SA. 
The majority of newly diagnosed HIV-positive individuals in the 35 clinics presented for HIV care late in the course of HIV infection. Extremely late presentation for HIV care is disproportionately prevalent among older males. Facilities in townships and inner cities have a high prevalence of extremely late presentation. These findings are major impediments to reaching the targets set in the 90-90-90 strategy, achieving universal viral suppression, and significantly changing the trajectory of the HIV epidemic. There is a need to focus policy and programmatic efforts towards realigning the strategies of the HCT services so that they specifically target individuals and geographical locations that exhibit a high likelihood of late presentation to HIV care. Policies should be developed to incentivise men towards early engagement with the health system. Until late presentation to HIV care is urgently prioritised and drastically reduced in SA, efforts to avert numerous preventable deaths and slow the HIV/AIDS epidemic may continue to be less effective.

\begin{abstract}
Acknowledgements. None.
Author contributions. HNF conceptualised the research approach and provided leadership and guidance during development of this manuscript. ART compiled the literature review, developed the analysis plan, carried out multiple statistical analysis, developed the description of the statistical output and composed the discussion and recommendation sections of the manuscript. YP, AL, MC and AG made extensive input to the study approach, literature review, analysis plan, presentation of data and recommendations during the development of the manuscript. SAM, MBM, CTB and NTH reviewed the manuscript and made input into and organised the reference list.
\end{abstract}

Funding. This research work was made possible through the support provided by the President's Emergency Plan for AIDS Relief through the Centers for Disease Control and Prevention (CDC) under a cooperative agreement (grant no. 5U2GGH000391). The funder provided technical oversight during the development of the study design, the data analysis and the preparation of the manuscript. The opinions expressed are those of the authors and do not necessarily reflect the views of the CDC.

Conflicts of interest. None.

1. Human Sciences Research Council. South African National HIV Prevalence, Incidence and Behaviour Survey. Pretoria: HSRC, 2014. http://www.hsrc.ac.za/en/research-data/view/6871 (accessed 20 June 2016).

2. South African National AIDS Council. The National HIV Counselling and Testing Campaign Strategy. Pretoria: SANAC, 2010. https://www.westerncape.gov.za/Other/2010/6/hct_campaign_ strategy_2_3_10_final.pdf (accessed 10 December 2016).

3. Joint United Nations Programme on HIV/AIDS. 90-90-90 - an Ambitious Treatment Target to Help End the AIDS Epidemic. Geneva: UNAIDS, 2014. http://www.unaids.org/en/resources/ documents/2014/90-90-90 (accessed 15 January 2016).

4. Cohen MS, Chen YQ, McCauley M, Gamble T, Hosseinipour MC, Kumarasamy N. Prevention of HIV-1 infection with early antiretroviral therapy. N Engl J Med 2011;356(6):493-505. https://doi org/10.1056/NEJMoal105243

5. Fleishman JA, Yehia BR, Moore RD, Gebo KA. The economic burden of late entry into medical care for patients with HIV infection. Med Care 2010;48(12):1071-1079. https://doi.org/10.1097/ MLR.0b013e3181f81c4a

6. Nadiaye B, Salleron J, Vincent A, et al. Factors associated with presentation to care with advanced HIV disease in Brussels and Northern France. BMC Infect Dis 2011;11:11. https://doi.org/10.1186/1471disease in $\mathrm{B}$

7. Dickson NP, McAllister S, Sharples K, Paul C. Late presentation of HIV infection among adults in New Zealand 2005 - 2010. HIV Med 2011;13(3):182-189. https://doi.org/10.1111/j.1468-1293.2011.00959.

8. Grangeiro A, Escuder MM, Pereira JCR. Late entry into HIV care: Lessons from Brazil, 2003 to 2006 BMC Infect Dis 2012;12:99. https://doi.org/10.1186/1471-2334-12-99

9. Gill VS, Lima VD, Zhang W, et al. Improved virological outcomes in British Columbia concomitant with decreasing incidence of HIV type 1 drug resistance detection. Clin Infect Dis 2010;50(1):98-105. https://doi.org/10.1086/648729

10. Moupali DM, Chu PL, Santos G-M, et al. Decreases in community viral load are accompanied by reductions in new HIV infections in San Francisco. PLoS One 2010;5(6):el1068. https://doi org/10.1371/journal.pone.0011068

11. Donnell D, Baeten JM, Kiarie J, et al. Heterosexual HIV-1 transmission after initiation of antiretroviral therapy: A prospective cohort analysis. Lancet 2010;375(9731):2092-2098. https://doi.org/10.1016/ S0140-6736(10)60705-2

12. Cohen MS, Chen YQ, McCauley M, et al. Prevention of HIV-1 infection with early antiretroviral therapy. N Engl J Med 2011;356(6):493-505. https://doi.org/10.1056/NEJMoa1105243
13. Anglemyer A, Rutherford GW, Easterbrook PJ, et al. Early initiation of antiretroviral therapy in HIV-infected adults and adolescents: A systematic review. AIDS 2014;28(2):S105-S118. https://doi. org/10.1097/QAD.0000000000000232

14. Tuboi SH, Schechter M, McGowan CC, et al. Mortality during the first year of potent antiretroviral therapy in HIV-1-infected patients in 7 sites throughout Latin America and the Caribbean. J Acquir Immune Defic Syndr 2009;51(5):615-623. https://doi.org/10.1097/QAI.0b013e3181a44foa

15. Harrison KM, Song R, Zhang X. Life expectancy after HIV diagnosis based on national HIV surveillance data from 25 states, United States. J Acquir Immune Defic Syndr 2007;53(1):124 -130.
s. surveillance data from 25 states, United States.
https://doi.org/10.1097/QAI.0b013e3181b563e7

16. Lawn SD, Little F, Bekker LG, et al. Changing mortality risk associated with CD4 cell response to antiretroviral therapy in South Africa. N Engl J Med 2009;23(3):335-342. http://doi.org/10.1097/ QAD.0b013e328321823f

17. Egger M, May M, Chêne G, et al. Prognosis of HIV-1-infected patients starting highly active antiretroviral therapy: A collaborative analysis of prospective studies. Lancet 2002;360(9327):119-129. https://doi.org/10.1016/S0140-6736(02)09411-4

18. Chasombat S, McConnell MS, Siangphoe U, et al. National expansion of antiretroviral treatment in Thailand, 2000 - 2007: Program scale-up and patient outcomes. J Acquir Immune Defic Syndr 2009;50(5):506-512. https://doi.org/10.1097/QAI.0b013e3181967602

19. Grangeiro A, Escuder MM, Menezes PR, Alencar R. Late entry into HIV care: Estimated impact on AIDS mortality rates in Brazil, 2003 - 2007. PLoS One 2011;6(1):e14585. https://doi.org/10.1371/ journal.pone.0014585

20. Leisegang R, Cleary S, Hislop M, Early and late direct costs in a Southern African antiretroviral treatment programme: A retrospective cohort analysis. PLoS Med 2009;6(12):e1000189. https://doi. treatment programme: A retrospective
org $/ 10.1371$ /journal.pmed.1000189

21. Attia S, Egger M, Müller M, Zwahlen M, Low N. Sexual transmission of HIV according to viral load and antiretroviral therapy: Systematic review and meta-analysis. AIDS 2009;23(11):1397-1404. https:// doi.org/10.1097/QAD.0b013e32832b7dca

22. Wood E, Kerr T, Marshall BDL. Longitudinal community plasma HIV-1 RNA concentrations and incidence of HIV-1 among injecting drug users: Prospective cohort study. BMJ 2009;338:b1649. https://doi.org/10.1136/bmj.b1649

23. Fang CT, Hsu HM, Twu SJ, et al. Decreased HIV transmission after a policy of providing free access to highly active antiretroviral therapy in Taiwan. J Infect Dis 2004;190(5):879-885. https://doi. org/10.1086/422601

24. National Department of Health, South Africa. National HIV Counselling and Testing Policy Guideline. Pretoria: NDoH, 2015. https://www.health-e.org.za/wp-content/uploads/2015/07/HCTGuidelines-2015.pdf (accessed 12 March 2016).

25. Statistics South Africa. Census 2011: Income dynamics and poverty status of households in South Africa. http://www.statssa.gov.za/publications/Report-03-10-10/Report-03-10-102014.pdf (accessed 4 July 2017).

26. National Department of Health, South Africa. National Consolidated Guidelines for the Prevention of Mother-to-child Transmission of HIV (PMTCT) and the Management of HIV in Children, Adolescents and Adults. Pretoria: NDoH, 2014. http://www.health.gov.za/index.php/2014-03-17-09-
Ans Adolescents and Adults. Pretoria: NDoH, 2014. http://www.health.gov.ZZ/ind

27. Hassan AS, Fielding KL, Thuo NM, Nabwera HM, Sanders EJ, Berkley JA. Early loss to follow-up of recently diagnosed HIV-infected adults from routine pre-ART care in a rural district hospital
of in Kenya: A cohort study. Trop Med Int Health 2012;17(1):82-93. https://doi.org/10.1111/j.13653156.2011 .02889

28. Evangeli M, Newell M-L, McGrath N. Factors associated with pre-ART loss-to-follow up in adults in rural KwaZulu-Natal, South Africa: A prospective cohort study. BMC Public Health 2016;16:358. https://doi.org/10.1186/s12889-016-3025-x

29. European Medicines Agency. Guideline on Missing Data in Confirmatory Clinical Trials. London: EMA, 2010. http://www.ema.europa.eu/docs/en_GB/document_library/Scientific_guideline/2010/09/ WC500096793.pdf (accessed 15 June 2017)

30. National Department of Health, South Africa. Operational Plan for Comprehensive HIV and AIDS Care, Management and Treatment for South Africa. Pretoria: NDoH, 2003. http://www.gov.za/sites/ www.gov.za/files/aidsoperationalplan1_0.pdf (accessed 20 July 2016).

31. Kigozi IM, Dobkin LM, Martin JN, et al. Late disease stage at presentation to an HIV clinic in the era of free antiretroviral therapy in sub-Saharan Africa. J Acquir Immune Defic Syndr 2009;52(2):280-289. https://doi.org/10.1097/QAI.0b013e3181ab6eab

32. Drain PK, Elena LE, Parker G, et al. Risk factors for late-stage HIV disease presentation at initial HIV Drain PK, Elena LE, Parker G, et al. Risk factors for late-stage HIV disease presentation at initial HIV
diagnosis in Durban, South Africa. PLoS One 2013;8(1):e55305. https://doi.org/10.1371/journal. pone. 0055305

33. Wanyenze RK, Kamya MR, Fatch R, et al. Missed opportunities for HIV testing and late-stage diagnosis among HIV-infected patients in Uganda. PLoS One 201 1;6(7):e21794. https://doi.org/10.1371/journal. pone.0021794

34. Lahuerta M, Wu Y, Hoffman S, et al. Advanced HIV disease at entry into HIV care and initiation of antiretroviral therapy during 2006 - 2011: Findings from four sub-Saharan African countries. Clin Infect Dis 2014;58(3):432-441. https://doi.org/10.1093/cid/cit724

35. Bor J, Rosen S, Chimbindi N, et al. Mass HIV treatment and sex disparities in life expectancy: Demographic surveillance in rural South Africa. PLoS Med 2015;12(11):e1001905. https://doi. org/10.1371/journal.pmed.1001905

36. Cornell M, Schomaker M, Belen GD, et al. Gender differences in survival among adult patients starting antiretroviral therapy in South Africa: A multicentre cohort study. PLoS Med 2012;9(9):e1001304. https://doi.org/10.1371/journal.pmed.1001304

37. Skovdal M, Campbell C, Madanhire C, et al. Masculinity as a barrier to men's use of HIV services in Zimbabwe. Global Health 2011;7:13. https://doi.org/10.1186/1744-8603-7-13

38. Gelaw YA, Senbete GH, Adane AA, Alene KA. Determinants of late presentation to HIV/AIDS care in Southern Tigray Zone, Northern Ethiopia: An institution based case-control study. AIDS Res Ther 2015;12:40. https://doi.org/10.1186/s12981-015-0079-2

39. Negin J, Cumming RG. HIV infection in older adults in sub-Saharan Africa: Extrapolating prevalence Negin J, Cumming RG. HIV infection in older adults in sub-Saharan Africa: Extrapolating prevalence
from existing data. Bull World Health Organ 2010;88(11):847-853. https://doi.org/10.2471/ BLT. existing

40. Lahuerta M, Ue F, Hoffman S, et al. The problem of late ART initiation in sub-Saharan Africa: A transient aspect of scale-up or a long-term phenomenon? I Health Care Poor Underserved 2013;24(1):359-383. https://doi.org/10.1353/hpu.2013.0014

41. Yazdanpanah Y, Lange J, Gerstoft J, Cairns G. Earlier testing for HIV - how do we prevent late presentation? Antivir Ther 2010;15(1):17-24. https://doi.org/10.3851/IMP1526

42. Partners in Sexual Health. A Review of Teenage Pregnancy in South Africa - Experiences of Schooling, and Knowledge and Access to Sexual \& Reproductive Health Services. Cape Town: PSH, 2013. http:// www.hst.org.za/publications/NonHST\%20Publications/Teenage\%20Pregnancy\%20in\%20South\%20 Africa\%20Final\%2010\%20May\%202013.pdf (accessed 26 July 2016).

43. National Department of Health, South Africa. National HIV Counselling and Testing Policy Guideline. Pretoria: NDoH, 2015. https://www.health-e.org.za/wp-content/uploads/2015/07/HCTGuidelines-2015.pdf (accessed 12 March 2016).

44. International Institute for Environment and Development. Urbanization and Development in South Africa: Economic Imperatives, Spatial Distortions and Strategic Responses. London: IIED, 2012. http://www.delog.org/cms/upload/pdf-africa/Urbanisation_and_Development_in_South_Africa_Economic_Imperatives_Spatial_Distortions_and_Strategic_Responses.pdf (accessed 8 May 2016). 
45. University of the Witwatersrand. Health Care Users' Experiences and Perceptions of Waiting Time at a Diabetes Clinic in an Academic Hospital. Johannesburg: University of the Witwatersrand, 2012. at a Diabetes Clinic in an Academic Hospital. Johannesburg: University of the Whtwatersrand, 2012. htp.//n Experiences $\% 20$ and $\% 20$ Perceptions $\% 200 \% \% 20$ Waiting $\% 20$ Ti.pdf? sequence $=1$ \&isAllowed $=y$
(accessed 16 December 2016).

46. Fomundam HN, Wutoh A, Tesfay A, et al. Surveillance of HIV-positive Pre-ART Persons in South Africa: Gap Analysis Report. Pretoria: Howard University, 2013.

47. Deblonde J, De Koker P, Hamers FF, Fontaine J, Luchters S, Temmerman M. Barriers to HIV testing in Europe: A systematic review. Eur J Public Health 2010;20(4):422-432. https://doi. org/10.1093/eurpub/ckp231

48. Netsanet F, Dessie A. Acceptance of referral for partners by clients testing positive for human Dessie A. Acceptance of referal Sovran S. Understanding culture and HIV/AIDS in sub-Saharan Africa. SAHARA J 2013;10(1):32-41. https://doi.org/10.1080/17290376.2013.807071
hovian

Accepted 29 August 2017. 